П. Г. Нелюбин. К вопросу об использовании компьютерных игр в обучении иностранному языку в средней школе

Научная статья

УДК 004.9:811

DOI: $10.18101 / 2307-3330-2021-3-75-77$

\title{
К ВОПРОСУ ОБ ИСПОЛЬЗОВАНИИ КОМПЬЮТЕРНЫХ ИГР В ОБУЧЕНИИ ИНОСТРАННОМУ ЯЗЫКУ В СРЕДНЕЙ ШКОЛЕ
}

\author{
(C) Нелюбин Павел Геннадьевич \\ учитель английского языка, \\ Гимназия № 5 имени Л. В. Усыниной \\ Россия, 671700, г. Северобайкальск, проспект 60 лет СССР, 12 \\ new-wirgil@yandex.ru
}

\begin{abstract}
Аннотация. Стили обучения, подходящие для поколения Z, включают обучение на практике и обучение при помощи различных гаджетов. Как показывают некоторые исследования, обучение в игре приносит пользу. Поэтому для изучения иностранных языков разработано множество мобильных приложений и компьютерных игр, например «Funland» и «Monkey Puzzles World Tour». К сожалению, эти игры не были разработаны с учетом потребностей учащихся школ. Игровое приложение «PowPow» было создано для поддержки студентов при изучении английской лексики. В этой игре есть три тематических раздела: дом, ресторан и космос. В каждом разделе учащиеся должны ответить на один вопрос за 30 секунд, чтобы завершить игру. В рамках проведенного исследования в эту игру играли учащиеся средней школы в возрасте 13 лет. После игры выяснилось, что все учащиеся были согласны с тем, что она мотивирует их к изучению английского языка.

Ключевые слова: обучение иностранному языку, инновационные технологии в средней школе, игры в образовании, PowPow.
\end{abstract}

\section{Для цитирования}

Нелюбин П. Г. К вопросу об использовании компьютерных игр в обучении иностранному языку в средней школе // Вестник Бурятского государственного университета. Образование. Личность. Общество. 2021. № 3. С. 75-77.

В последние годы исследования эффективности обучения на основе цифровых игр (DGBL) значительно увеличились. Образовательные игры ориентированы на структурированное и развлекательное игровое программирование, которое поддерживает игроков в процессе обучения до тех пор, пока не будет достигнута указанная цель обучения. В этом контексте исследователи изучают, как интерактивная игра помогает учащимся средней школы изучать лексику английского языка. Более того, учащимся нужны более «интересные» средства обучения при изучении иностранного языка, чтобы избежать скуки, которую они испытывают при обучении с использованием стандартных методов. Исследование, проведенное среди учащихся 7-х классов, показало, что на компетентность учащихся в изучении словарного запаса влияют внутренние и внешние факторы, в том числе мотивация учащихся, уровень концентрации, уровень сложности обучения слов, количество учащихся в классе и использование средств обучения. Результаты 
многих исследований доказали, что интерес учащихся возрастает по мере того как они догадываются, что игра увлекательна.

Эффективность обучения на основе компьютерных игр также измеряется путем тестирования игры учащимися. При сравнении тестов выявлено, что игра, используемая в качестве инструмента обучения, может повысить интерес и мотивацию учащихся.

Другое исследование показывает, что игровой подход мотивирует учащихся учиться, чем при неигровом подходе. Кроме того, мотивация и результаты достижения игрового процесса между мальчиками и девочками равны. Таким образом, интерес к игровому процессу появляется не только у мальчиков.

Исходя из вышеуказанных обстоятельств, предлагается альтернативный подход к обучению с использованием компьютерной игры.

Исследование проводилось в несколько этапов с участием учащихся разного возраста. Однако в настоящей статье приведены учащиеся двух 7-х классов средней школы, использующие «PowPow» в обучении, который состоит из трех тематических групп и девяти наборов мини-игр. Каждая игра начинается с ознакомления определенной темы. Пользователям дается некоторое время, чтобы изучить тему, прежде чем они применят знания в игре. Этот способ позволяет пользователям усваивать новые знания для достижения цели игры и получения «звездочек». Они могут выбрать тему и играть в игру в течение ограниченного времени. Игроки могут повторить игру, чтобы узнать, есть ли прогресс в завершении игры, отмечая время, необходимое для каждой игры. Это нужно для того, чтобы учащиеся могли вести себя более уверенно.

В результате учащиеся 7-х классов показали высокий уровень мотивации при изучении поставленной темы и в среднем проявили большую активность и заинтересованность предметом, нежели обычно. Мы не стали показывать итоги исследования в разрезе групп (классов) в дифференцированном виде, т. к. результаты практически идентичны.

Таким образом, традиционные подходы к обучению не соответствуют развитию технологий, особенно для учащихся современной школы. Игре «PowPow» удалось привлечь интерес учащихся к английскому языку и побудить их к его изучению. Кроме того, это игра может увеличить словарный запас учащихся. Однако необходимо улучшить игру, т. е. увеличить допустимое время, чтобы учащиеся больше внимания уделяли практике.

\section{Лuтература}

1. Wang Y. J., Shang H. F., Briody P. Investigating the impact of using games in teaching children English // International Journal of Learning \& Development. 2011. P. 127-141.

2. Rawendy D., Ying Y., Arifin Y., Rosalin K. Design and development game Chinese language learning with gamification and using mnemonic method // Procedia Computer Science. 2017. P. 61-67.

3. Papastergiou M. Digital game-based learning in high school computer science education: Impact on educational effectiveness and student motivation // Computers \& Education. 2009. P. $1-2$. 
П. Г. Нелюбин. К вопросу об использовании компьютерных игр в обучении иностранному языку в средней школе

Статья поступила в редакиию 18.11.2021; одобрена после рецензирования 22.11.2021; принята к публикации 07.12.2021.

\title{
ABOUT SOME QUESTIONS OF USING COMPUTER GAMES IN TEACHING A FOREIGN LANGUAGE IN SECONDARY SCHOOL
}

\author{
Pavel G. Nelyubin \\ English teacher \\ Usynina Gymnasium \# 5 of Severobaikalsk \\ 12 prospect 60 years of the USSR, Severobaikalsk, 671700 Russia \\ new-wirgil@yandex.ru
}

Learning styles that are suitable for generation $\mathrm{Z}$ are learning by doing and learning through gadgets and computer games. Learning through a game is more fun and beneficial, as proven by some studies. In foreign language learning there are many applications such as «Funland» and «Monkey Puzzles World Tour». Unfortunately, the application has not been developed based on the needs of school students. A game application, called «PowPow» has been developed to meet those needs in supporting students learn English vocabulary. This game has three different themes: house, restaurant and outer space. In each theme, students are motivated to play each prompt question in 30 seconds to complete the game. This application was played by secondary students aged 13 in the frames of the study. After playing the game, it is found out all students agree that this game motivates them to learn English.

Keywords: foreign language teaching, innovative technologies in secondary school, games in education, PowPow.

The article was submitted 18.11.2021; approved after reviewing 22.11.2021; accepted for publication 07.12.2021. 